\title{
Multiple Endocrine Neoplasia Type 2A with the Identical Somatic Mutation in Medullary Thyroid Carcinoma and Pheochromocytoma without Germline Mutation at the Corresponding Site in the $R E T$ Proto-oncogene
}

\author{
Hiroyoshi Akama, Takao Noshiro, Noriko Kimura*, Kazumasa Shimizu, Toshiya Watanabe, \\ Satoru Shibukawa, Shigeyasu Nakai, Wakako Miura, Sadayoshi Ito and Yukio Miura**
}

A germline mutation either in exon 10 or 11 of the RET proto-oncogene is found in the majority of patients with multiple endocrine neoplasia type $2 \mathrm{~A}$ (MEN 2A). A 41-year-old female patient was referred for further evaluation of incidentally discovered right adrenal tumor. She had bilateral adrenal pheochromocytomas and medullary thyroid carcinomas detected by endocrinological and radiological examination, and diagnosed as MEN 2A. Molecular genetic testing of the RET exons 10 and 11 exhibited the identical somatic missense mutation at codon 634 in both tumors but did not confirm germline mutations in the corresponding sites. Possible mechanisms for tumorigenesis in this patient are discussed.

(Internal Medicine 38: 145-149, 1999)

Key words: hypertension, multiple endocrine neoplasia (MEN) type 2A, Sipple's syndrome

\section{Introduction}

Multiple endocrine neoplasia type $2 \mathrm{~A}(\mathrm{MEN} 2 \mathrm{~A})$ is a rather rare autosomal dominant syndrome which is characterized by the triad of medullary thyroid carcinoma (MTC), pheochromocytoma and parathyroid hyperplasia or adenoma. Missense germline mutations in one of five cysteine codons either in exon 10 or exon 11 of the $R E T$ proto-oncogene have been identified in more than $95 \%$ of patients with MEN $2 \mathrm{~A}(1-6)$. Identification of germline RET mutations in MEN 2A has changed the strategy for the management of this syndrome and allowed DNA-based subclinical diagnosis followed by an even prophylactic surgical treatment (6-11).

For editorial comment, see p 80.

All of the patients with MEN 2A, however, do not have germline mutations in exons 10 and 11 of the RET protooncogene $(4,5)$. We report a 41-year-old woman with MEN 2A who did not have a germline mutation in the "hot spots", codons $609,611,618$ and 620 in exon 10 and 634 in exon 11, but did have the identical somatic mutation at codon 634 in both pheochromocytoma and MTC tumors. In addition, she did not have an apparent family history of MEN 2A. Here, we present this rare case of MEN 2A and discuss the tumorigenesis of this syndrome.

\section{Case Report}

A 41-year-old woman complained of right upper abdominal pain and consulted her physician. An abdominal ultrasonography demonstrated a right adrenal mass of $4 \mathrm{~cm}$ in diameter. She was then referred to the Tohoku University Hospital for further examinations on May 2, 1997. She did not have a particular family history of hypertension or endocrine diseases except that her father died of myocardial infarction. On admission, a $1 \mathrm{~cm}$-sized elastic mass was palpated in the right lobe of the thyroid gland. No developmental abnormalities such as mucosal neuromas, an unusual facial appearance, or marfanoid habitus, were observed. Blood pressure and heart rate were almost normal during her hospitalization. The platelet count was elevated to $6.02 \times 10^{5} / \mathrm{ml}$. The plasma level of total choles-

From the Second Department of Internal Medicine, *the Department of Pathology, Tohoku University School of Medicine and **the Department of Informatics on Pathophysiology, Tohoku University Graduate School of Information Science, Sendai

Received for publication May 15, 1998; Accepted for publication October 20, 1998

Reprint requests should be addressed to Dr. Takao Noshiro, the Department of Informatics on Pathophysiology, Tohoku University Graduate School of Information Science, Kawauchi Kita-Campus, Aoba-Ku, Sendai 980-8576 
terol was $257 \mathrm{mg} / \mathrm{dl}$. Oral glucose tolerance test showed a pattern of impaired glucose tolerance. Plasma norepinephrine (NE) and epinephrine (E) were markedly increased, 2,070 pg/ $\mathrm{ml}$ (normal, $<250 \mathrm{pg} / \mathrm{ml}$ ) and 1,650 pg/ml (normal, $<100 \mathrm{pg}$ / $\mathrm{ml}$ ), respectively. The values of 24-hour urinary excretion of $\mathrm{NE}, \mathrm{E}$ and vanillylmandelic acid were all increased at $577 \mu \mathrm{g} /$ day (normal, $<100 \mu \mathrm{g} / \mathrm{day}$ ), $604 \mu \mathrm{g} /$ day (normal, $<15 \mu \mathrm{g} /$ day) and $11.3 \mathrm{mg} / \mathrm{day}$ (normal, $<8 \mathrm{mg} /$ day), respectively. The serum calcitonin level $(1,428 \mathrm{pg} / \mathrm{ml})$ was markedly elevated, whereas intact parathyroid hormone was within the normal range. No abnormalities of plasma electrolytes were detected ( $\mathrm{Na} 137$ $\mathrm{mEq} / l, \mathrm{~K} 4.5 \mathrm{mEq} / \mathrm{l}, \mathrm{Cl} 100 \mathrm{mEq} / \mathrm{l}, \mathrm{Ca} 9.4 \mathrm{mg} / \mathrm{dl}, \mathrm{P} 3.4 \mathrm{mg} / \mathrm{dl}$ ).

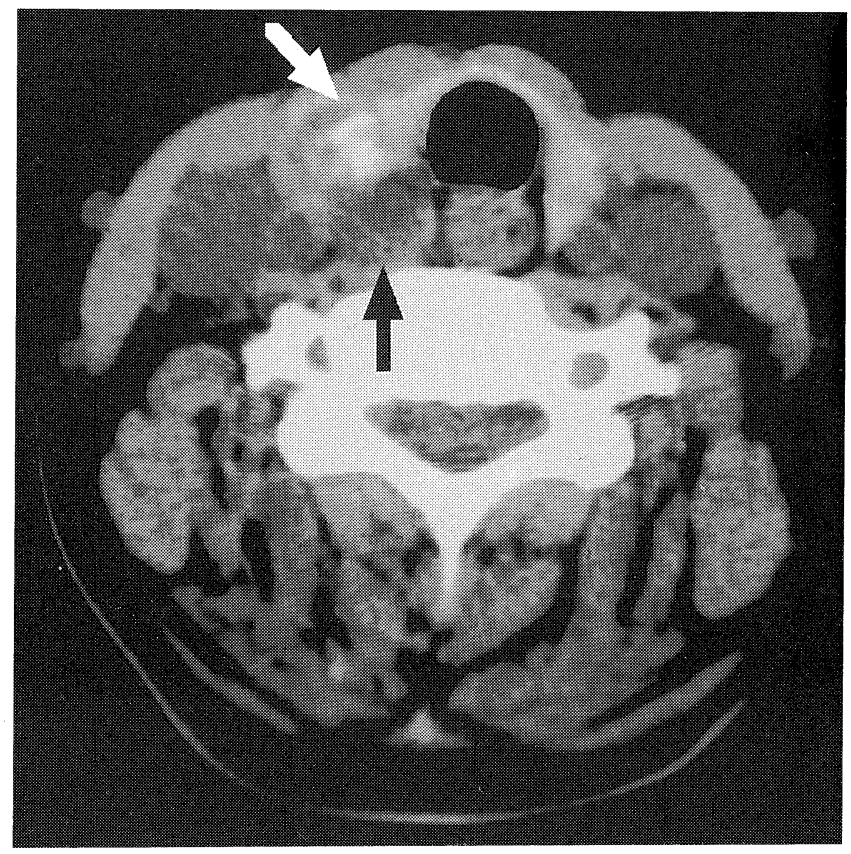

A

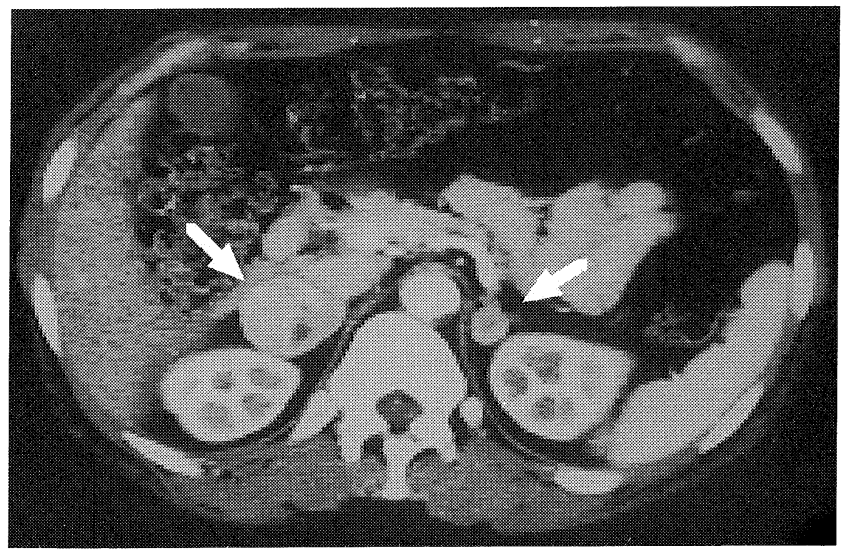

$\mathrm{B}$

Figure 1. Enhanced CT scans of the neck (A) and the abdomen (B). Arrows indicate medullary thyroid carcinomas (A) and pheochromocytomas (B).

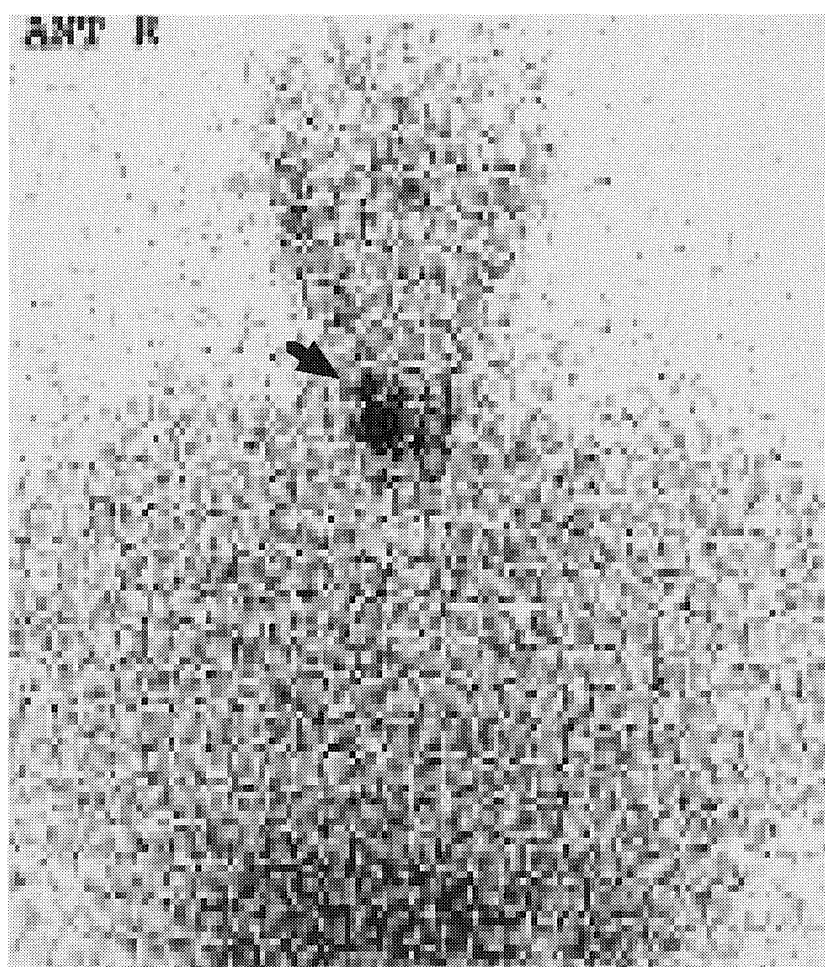

A

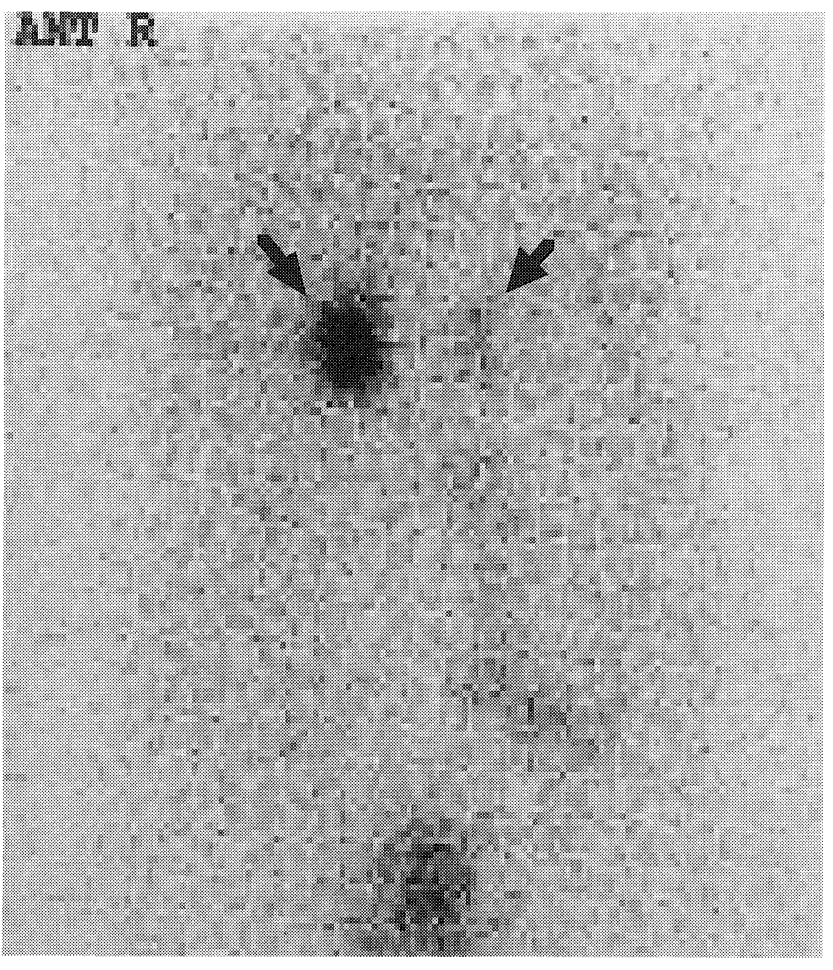

B

Figure 2. ${ }^{131}$ I-metaiodobenzylguanidine scintigraphy of the neck (A) and the abdomen (B). Arrows indicate medullary thyroid carcinomas (A) and pheochromocytomas (B). 
The carcinoembryonic antigen was elevated to $48.1 \mathrm{ng} / \mathrm{ml}$.

The abdominal computed tomographic (CT) scans confirmed bilateral adrenal tumors well enhanced with contrast medium (Fig. 1). The cervical CT scan revealed well enhanced multiple neoplastic lesions in both lobes of the thyroid gland (Fig. 1). ${ }^{131}$ I-metaiodobenzylguanidine scintigraphy indicated distinct accumulation in both lobes of the thyroid gland and in bilateral adrenal glands (Fig. 2). Based on these data, she was diagnosed as MEN 2A without hyperparathyroidism. Bilateral adrenalectomy and total thyroidectomy were performed on June 18, 1997.

Histopathological examination revealed pheochromocytomas in the bilateral adrenal glands and multicentric MTCs in both lobes of the thyroid gland with diffuse hyperplasia of parafollicular C-cells in all slides of the specimens (Fig. 3). Neither parathyroid hyperplasias nor adenomas were observed.

Direct DNA sequence analysis of exons 10 and 11 in the RET

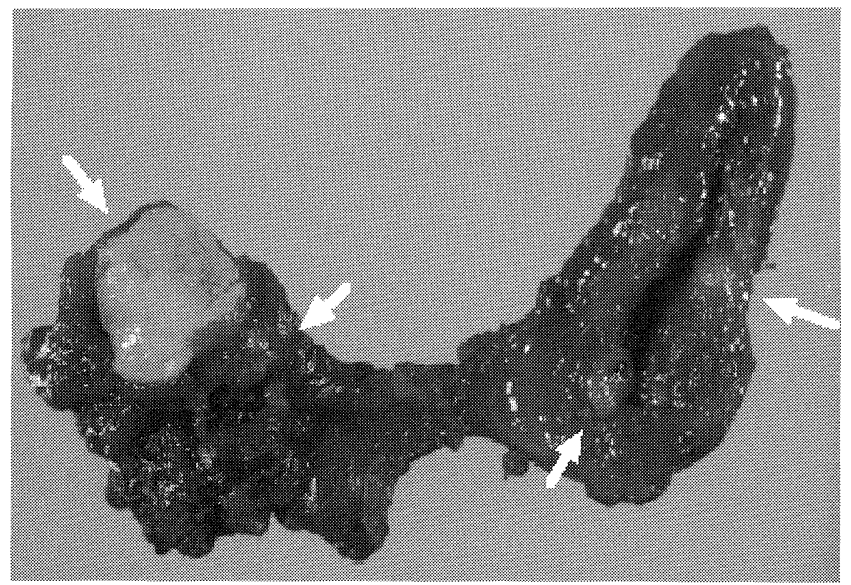

A

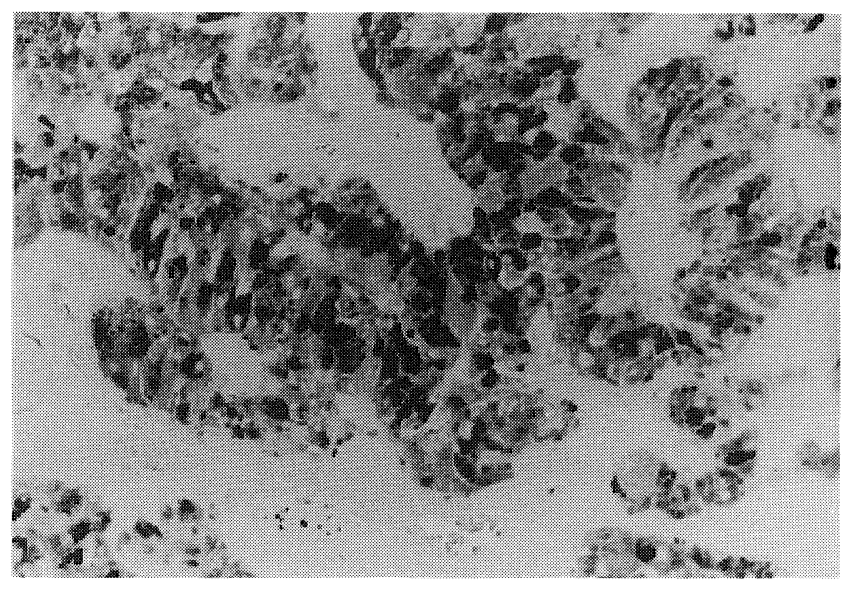

B

Figure 3. A) Macroscopic findings of medullary thyroid carcinomas (arrows). Note the multicentric tumors. B) Microscopic findings of the medullary thyroid carcinomas (chromogranin A stain, $\times 200$ ). proto-oncogene showed the somatic mutation of TGC (cysteine) to TAC (tyrosine) at codon 634 in exon 11 in the tumor specimens of both pheochromocytoma and MTC, whereas germline mutations at the corresponding site of the RET protooncogene could not be detected in her leukocytes or normal thyroid tissues (Fig. 4). Direct DNA sequence analysis of the RET proto-oncogene was also performed in all of the firstdegree relatives except her father who had died of myocardial infarction and her sister, but no germline mutations in exon 10 or 11 in the family members examined could be found.

\section{Discussion}

Germline mutations in the RET proto-oncogene, which encodes the transmembrane-receptor tyrosine kinase, are associated with MEN 2A in the autosomal dominant manner. A germline missense mutation either in exon 10 (codons 609, 611, 618 , and 620) or 11 (codon 634) of the RET proto-oncogene has been identified in more than $95 \%$ of the patients with MEN 2A (3-5) since the first report of Mulligan et al (1). The present case showed a typical phenotype of MEN 2A, multicentric MTCs with diffuse parafollicular C-cell hyperplasia and bilateral adrenal pheochromocytomas, and the identical somatic missense mutation for TGC (cysteine) to TAC (tyrosine) at codon 634 in exon 11 of the RET proto-oncogene was found in MTC and pheochromocytoma tissues, strongly suggesting that a common genetic abnormality may be involved in the etiology of these tumors. However, she did not have any germline mutations at the corresponding site of the RET proto-oncogene; this was apparently a sporadic case as far as we have examined.

When a patient has both MTC and pheochromocytoma without any germline mutations of the RET proto-oncogene, as in the present case, one may first consider the possibility that sporadic pheochromocytoma and sporadic MTC co-exist accidentally. To our knowledge, however, there have been no reports demonstrating the identical somatic mutations of the $R E T$ proto-oncogene in a patient with both sporadic pheochromocytoma and sporadic MTC. Several investigators have reported that somatic mutations of the RET proto-oncogene are detected in $23-60 \%$ of sporadic MTCs (12-18) and in 8-20\% of sporadic pheochromocytomas (19-21). In sporadic MTCs, the most frequent somatic mutation of the RET proto-oncogene is at codon 918 (Met-Thr) and a mutation at codon 634 is rather rate (12-18). By contrast, the germline mutation at codon 634 is most frequently detected in $84 \%$ of the patients with MEN $2 \mathrm{~A}$ and considered to be closely related to the pathogenesis of MEN 2A (2-5). Furthermore, the present case had both bilateral pheochromocytoma and multicentric MTCs with diffuse parafollicular C-cell hyperplasia which is considered to be a preceding state of MTC. Taken together, it is less likely that sporadic pheochromocytoma and sporadic MTC co-exist accidentally in this case, but it is more likely that etiologies other than germline mutations of the RET proto-oncogene may have been involved in the development of the tumors.

The mechanism of tumorigenesis in the patient is unclear, but several possibilities can be speculated. First, the missense 


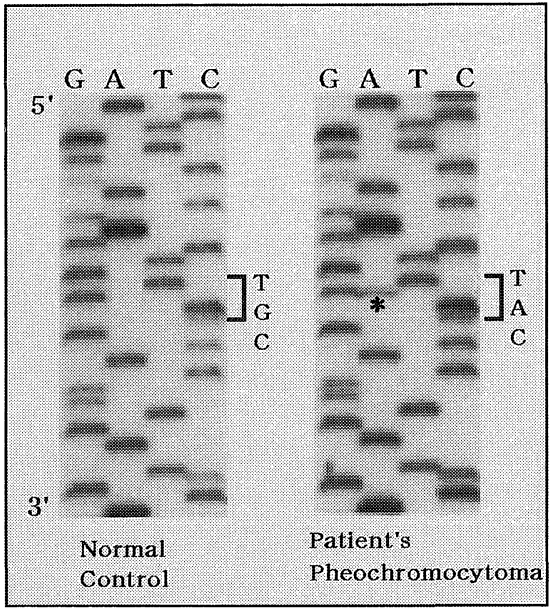

A

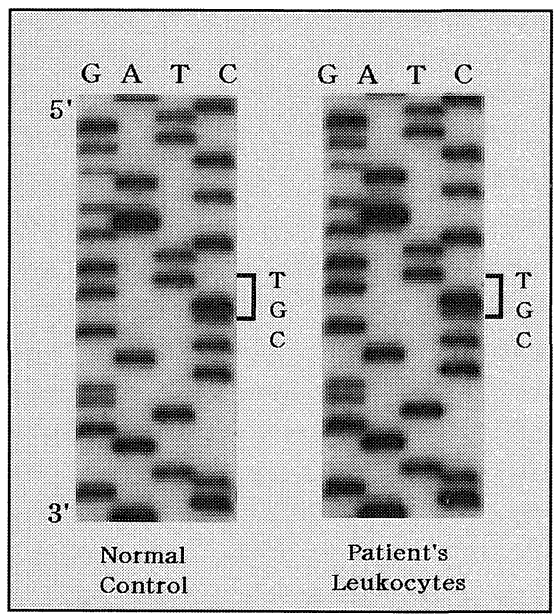

C

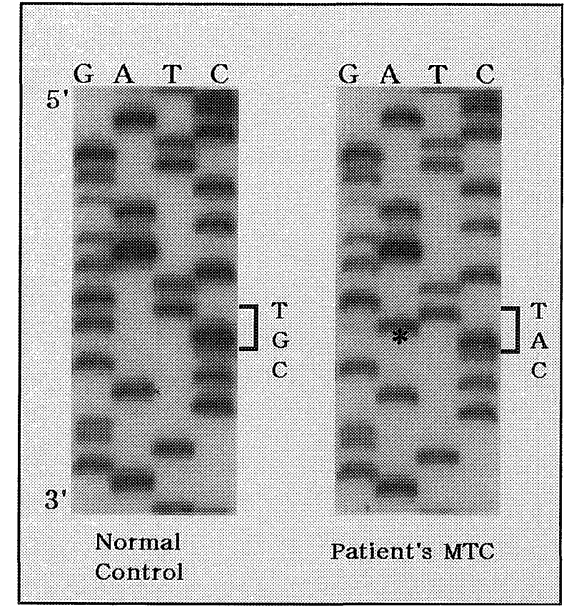

B

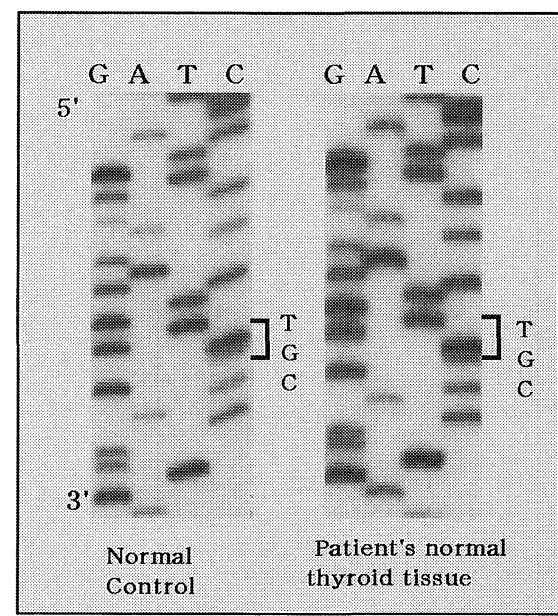

$\mathrm{D}$

Figure 4. Sequence analysis of exon 11 of the RET proto-oncogene. A) patient's pheochromocytoma, B) patient's medullary thyroid carcinoma (MTC), C) patient's leukocytes, D) patient's normal thyroid tissue. Note that both the pheochromocytoma and MTC have an identical somatic mutation for TGC (cysteine) to TAC (tyrosine) at codon 634 in exon 11 of the $R E T$ proto-oncogene, whereas no germline mutation was detected at the corresponding site of the RET proto-oncogene.

somatic mutation of the RET proto-oncogene detected in both MTC and pheochromocytoma might have occurred during the differentiation of the neural crest in her embryonic period since both parafollicular C-cells and adrenomedullary cells originate from the neural crest (22). Second, an unknown mutation of genes including the RET proto-oncogene might have caused both MTC and pheochromocytoma. As we did not examine the entire exons of the RET proto-oncogene, we can not completely exclude the possibility of the existence of a germline mutation other than exon 10 or 11 in the RET proto-oncogene in the present case. Quite recently, codons 790 and 791 in exon 13 of the RET proto-oncogene, a new hot spot for mutations causing MEN 2A, have been reported by Berndt et al (23). To date, however, the germline mutation at codon 918 in exon 16 found in patients with MEN 2B has not been detected as a cause of MEN 2A. Glial cell line-derived neurotrophic factor (GDNF) and its receptor molecule GDNFR- $\alpha$, have recently been identified as members of the RET ligand binding complex (2426). Therefore, the genes encoding both GDNF and GDNFR$\alpha$ may be strong candidates playing a role in the pathogenesis of MEN 2A families without RET germline mutation. Recently, Marsh et al (27) have studied the sequence analysis for GDNF gene in 9 cases of MEN 2A without RET germline mutation, but no mutations of GDNF gene were detected. We did not analyze GDNF or GDNFR- $\alpha$ gene in this case. The existence of mutation of GDNF or GDNFR- $\alpha$ gene in the present case, if any, can not explain the identical somatic mutation of the RET proto-oncogene in both MTC and pheochromocytoma. 


\section{MEN 2A without RET Germline Mutation}

Since MEN type 2A is of autosomal dominant heredity, an apparently sporadic case of the disease is rare. Actually, sporadic patients with MEN 2A were reported in only 6 out of 100 patients from 40 families (28). A de novo germline mutation in the $R E T$ proto-oncogene occurred during the embryonic period or insufficient familial screening may result in most of the sporadic MEN 2A. In the present case, although her father had died of myocardial infarction and his genetic profile was unclear, she did not have an apparent family history of MEN 2A. Therefore, it is unlikely that either of her parents have germline mutations in the hot spot of the RET proto-oncogene, because she did not have germline mutations in exon 10 or 11 in the RET proto-oncogene.

In summary, we report a rare case of a patient with MEN 2A who did not have any germline mutations in hot spot of the RET proto-oncogene but had the identical somatic mutation at codon 634 in exon 11 both in MTC and pheochromocytoma.

\section{References}

1) Mulligan LM, Kwok JBJ, Healey CS, et al. Germline mutations of the ret protooncogene in multiple endocrine neoplasia type $2 \mathrm{~A}$ (MEN 2A). Nature 363: 458-460, 1993.

2) Mulligan LM, Eng C, Healey CS, et al. Specific mutations of the RET proto-oncogene are related to disease phenotype in MEN 2A and FMTC. Nat Genet 6: 70-74, 1994.

3) Eng C. The RET proto-oncogene in multiple endocrine neoplasia type 2 and Hirschsprung's disease. N Engl J Med 335: 943-951, 1996.

4) Eng C, Clayton D, Schuffenecker I, et al. The relationship between specific $R E T$ proto-oncogene mutations and disease phenotype in multiple endocrine neoplasia type 2. International RET mutation consortium analysis. JAMA 276: 1575-1579, 1996.

5) Frank-Raue K, Höppner W, Frilling A, et al. Mutation of the RET protooncogene in German multiple endocrine neoplasia families: Relation between genotype and phenotype. J Clin Endocrinol Metab 81: 1780$1783,1996$.

6) Neumann HPH, Eng C, Mulligan LM, et al. Consequences of direct genetic testing for germline mutations in the clinical management of families with multiple endocrine neoplasia, type II. JAMA 274: 1149 1151, 1995.

7) Decker RA, Peacock ML, Borst MJ, Sweet JD, Thompson NW. Progress in genetic screening of multiple endocrine neoplasia type $2 \mathrm{~A}$ : Is calcitonin testing obsolete? Surgery 118: 257-263, 1995.

8) Frank-Raue K, Kratt T, Höppner W, Buhr H, Ziegler R, Raue F. Diagnosis and management of pheochromocytomas in patients with multiple endocrine neoplasia type 2 - relevance of specific mutations in the RET protooncogene. Eur J Endocrinol 135: 222-225, 1996.

9) Ledger GA, Khosla S, Lindor NM, Thibodeau SN, Gharib H. Genetic testing in the diagnosis and management of multiple endocrine neoplasia type II. Ann Intern Med 122: 118-124, 1995.

10) Lips CJM, Landsvater RM, Höppener JWM, et al. Clinical screening as compared with DNA analysis in families with multiple endocrine neoplasia type 2A. N Engl J Med 331: 828-835, 1994.

11) Wells SA Jr, Chi DD, Toshima K, et al. Predictive DNA testing and prophylactic thyroidectomy in patients at risk for multiple endocrine neoplasia type 2A. Ann Surg 220: 237-247, 1994.

12) Kimura T, Yoshimoto K, Yokogoshi Y, Saito S. Mutations in the cysteine-rich region of the RET proto-oncogene in patients diagnosed as having sporadic medullary thyroid carcinoma. Endocr J 42: 517-525, 1995.

13) Eng C, Smith DP, Mulligan LM, et al. Point mutation within the tyrosine kinase domain of the RET proto-oncogene in multiple endocrine neoplasia type 2B and related sporadic tumors. Hum Mol Genet 3: 237-241, 1994.

14) Hofstra RMW, Stelwagen T, Stulp RP, et al. Extensive mutation scanning of ret in sporadic medullary thyroid carcinoma and of RET and VHL in sporadic pheochromocytoma reveals involvement of these genes in only a minority of cases. J Clin Endocrinol Metab 81: 2881-2884, 1996.

15) Landsvater RM, de Wit MJ, Zewald RA, et al. Somatic mutations of the $R E T$ proto-oncogene are not required for tumor development in multiple endocrine neoplasia type 2 (MEN 2) gene carriers. Cancer Res 56: 48534855, 1996.

16) Marsh DJ, Andrew SD, Eng C, et al. Germline and somatic mutations in an oncogene: RET mutations in inherited medullary thyroid carcinoma. Cancer Res 56: 1241-1243, 1996.

17) Romei $\mathrm{C}$, Elisei R, Pinchera A, et al. Somatic mutations of the RET protooncogene in sporadic medullary thyroid carcinoma are not restricted to exon 16 and are associated with tumor recurrence. J Clin Endocrinol Metab 81: 1619-1622, 1996.

18) Wohllk N, Cote GJ, Bugalho MMJ, et al. Relevance of RET protooncogene mutations in sporadic medullary thyroid carcinoma. J Clin Endocrinol Metab 81: 3740-3745, 1996.

19) Beldjord $\mathrm{C}$, Desclaux-Arramond $\mathrm{F}$, Raffin-Sanson $\mathrm{M}$, et al. The RET proto-oncogene in sporadic pheochromocytomas: Frequent MEN 2-like mutations and new molecular defects. J Clin Endocrinol Metab 80: 20632068, 1995.

20) Lindor NM, Honchel R, Khosla S, Thibodeau SN. Mutations in the RET proto-oncogene in sporadic pheochromocytomas. J Clin Endocrinol Metab 80: 627-629, 1995.

21) Yoshimoto $\mathrm{K}$, Tanaka $\mathrm{C}$, Hamaguchi $\mathrm{S}$, et al. Tumor-specific mutations in the tyrosine kinase domain of the RET proto-oncogene in pheochromocytomas of sporadic type. Endocr J 42: 265-270, 1995.

22) Gagel RF. RET proto-oncogene mutations and endocrine neoplasia: a story intertwined with neural crest differentiation. Endocrinology 137: 1509-1511, 1996.

23) Berndt I, Reuter M, Saller B, et al. A new hot spot for mutations in the RET proto-oncogene causing familial medullary thyroid carcinoma and multiple endocrine neoplasia type 2A. J Clin Endocrinol Metab 83: 770-774, 1998.

24) Durbec P, Marcos-Gutierrez CV, Kilkenny C, et al. GDNF signalling through the Ret receptor tyrosine kinase. Nature 381: 789-793, 1996.

25) Jing $\mathrm{S}$, Wen D, Yu Y, et al. GDNF-induced activation of the Ret protein tyrosine kinase is mediated by GDNFR- $\alpha$, a novel receptor for GDNF. Cell 85: 1113-1124, 1996.

26) Treanor JJS, Goodman L, de Sauvage F, et al. Characterization of a multicomponent receptor for GDNF. Nature 382: 80-83, 1996.

27) Marsh DJ, Zheng Z, Arnold A, et al. Mutation analysis of glial cell linederived neurotrophic factor, a ligand for an RET/coreceptor complex, in multiple endocrine neoplasia type $2 \mathrm{~A}$ and sporadic neuroendocrine tumors. J Clin Endocrinol Metab 82: 3025-3028, 1997.

28) Casanova S, Rosenberg-Bourgin M, Farkas D, et al. Pheochromocytoma in multiple endocrine neoplasia type 2A: survey of 100 cases. Clin Endocrinol 38: 531-537, 1993. 